\title{
Factors affecting satisfaction with emergency medical services among elderly Koreans
}

\author{
Ju Moon Park ${ }^{1 *}$ and Aeree Sohn ${ }^{2}$ \\ ${ }^{1}$ Department of Urban Policy and Administration, Urban Science Institute, Incheon National University, Incheon, Korea \\ ${ }^{2}$ Department of Health \& Human Performance, Sahmyook University, Seoul, Korea
}

\begin{abstract}
Objective: Using representative nationwide Korea Health Panel Survey data, this study examined differences and factors influencing the level of satisfaction with EMS among the elderly.

Method: This study used cross-sectional analyses with 2016 KHPS data released to the public in 2019. Using both descriptive and logistic regression analyses, this paper analyzed data from the 2016 Korean Health Panel Survey $(\mathrm{n}=4,216)$.

Results: Among 4,216 respondents, 15.09\% were dissatisfied and 84.91\% were satisfied. In logistic multivariate analysis, Age (OR, 0.817; 95\%CI:0.679-0.983; $\mathrm{p}=0.032$ ), education (OR, 0.849; 095\%CI:0.773-0.933; $\mathrm{p}<0.01)$, number of ER visits (OR, 0.754;95\%CI:0.619-0.919; $\mathrm{p}<0.01)$, whether the respondent is a patient or a proxy (OR, 0.629;95\%CI:0.516-0.768; p<0.01), reasons for visiting ER (OR, 0.708; 95\%CI:0.565-0.888; p<0.01), waiting time in the ER (OR, 0.759; 95\%CI:0.6130.939; $\mathrm{p}=0.011$, and post-services measures (OR, 0.862;95\%CI:0.782-0.950; $\mathrm{p}<0.01)$ were inversely associated with the satisfaction of EMS. Residence (OR, 1.325; 95\%CI:1.287-1.616; $\mathrm{p}<0.01)$ and health status (OR, 1.353;95\%CI:1.125-1.627; $<<0.01)$ were significantly associated with EMS satisfaction.

Conclusion: Characteristic variables such an age, residence, health status, whether the respondent is a patient or a proxy, and number of ER visits had significant differences in EMS satisfaction. In addition, waiting time, reasons for visiting the emergency room, and post-service measures were factors that affected satisfaction that could be used as an indicator of the quality of emergency medical services.
\end{abstract}

\section{Introduction}

Along with the increased risk of social disasters and natural disasters such as typhoons and earthquakes, acute and chronic diseases caused by aging require rapid emergency medical services (hereinafter EMS). Concerns are also growing over the recent spread of COVID-19, as it is fatal, and the elderly are highly vulnerable to it. Medical services for elderly emergency patients that may occur in these situations are of the utmost importance.

According to an announcement by the National Emergency Medical Center, the total number of emergency room (hereinafter ER) visitors increased 39 percent in a decade, from about 7,480,000 in 2005 to $10,380,000$ in 2014 [1]. Despite such a surge in emergency patients, the quality of EMS is unsatisfactory, and users are complaining about ER overcrowding, and thus the overall satisfaction with hospital medical services is decreasing [2]. EMS not only greatly affects satisfaction with hospital services, but also serves as a means of assessing the services experienced by emergency patients or their guardians in emergency centers [3]. In addition, satisfaction with medical services is not a sufficient indicator of medical services in itself, but can be used as a basis for assessing the quality of services [4]. In fact, the satisfaction level of EMS is used as a major indicator in studies that assess the quality of EMS and has been used as a policy basis for improving the quality of services by identifying factors that have an impact on the services [5]. In a previous study, skilled interpersonal relationships, sufficient information provision, and reduction of waiting times in other countries [6-8] were the main factors that enhanced the satisfaction of ER patients, while in Korea, waiting time, medical staff's kindness, ER environment, hospital image, post-ER process, transportation to the ER, delays and post-service measures affected emergency medical satisfaction $[2,3,9-12]$.

Since the needs of the elderly in the ER are physically and psychologically urgent, their satisfaction with the services provided in the ER may be more important than the satisfaction of an outpatient or inpatient. However, unlike outpatient visits or hospitalization, there is a short time to provide medical services in the ER and limited user selection due to the specificity of emergency situations, resulting in a lack of complete reflection of the individual needs of patients and reduced satisfaction of ER users $[6,7,13]$.

In addition, in emergency medicine, senior citizens are classified as a special group because elderly patients are exposed to non-typical symptoms when they are treated for diseases focusing on one main symptom, resulting in serious consequences compared to younger people. Due to the non-typical manifestation of a disease, emergency care for elderly patients often takes a lot of time, is difficult to examine and treat, and requires many diagnostic methods. Also, senior citizens are likely to experience communication problems due to sensory disorders such as cognitive impairment and hearing loss. [14]. These

${ }^{\star}$ Correspondence to: Ju Moon Park, Department of Urban Policy and Administration, Incheon National University, 119 Academy-ro, Yeonsu-gu, Incheon 402-750, South Korea, E-mail: jumoonpark@incheon.ac.kr

Key words: emergency room, satisfaction, emergency medical services, factors, elderly

Received: July 28, 2020; Accepted: August 10, 2020; Published: August 14, 2020 
health- and disease-related characteristics of the elderly affect the time spent in the ER or hospitalization and discharge after treatment, and the complexity of emergency care can make it more difficult to provide quality emergency services, thereby affecting service satisfaction [5].

Given that medical services should be provided from a customer's point of view according to the needs of customers, it is necessary to understand the satisfaction level of EMS according to the characteristics of the elderly and identify the factors that affect them, which are necessary to improve the quality of customer-tailored EMS in the future. However, most of the previous studies on the satisfaction level of EMS have been conducted on those who use emergency rooms, which have a small number of samples, and are limited to those who use ERs in general hospitals in certain areas, and research using representative national survey data is extremely rare. Therefore, using representative nationwide Korea Health Panel Survey (hereinafter KHPS) data, this study examined differences and factors influencing the level of satisfaction with EMS among the elderly.

\section{Methods}

\section{Study sample}

This study used cross-sectional analyses with 2016 KHPS data released to the public in 2019. The Health Panel is a panel survey that has been conducted by the Korea Institute for Health and Social Affairs and the National Health Insurance Corporation since 2008 for the purpose of identifying the actual status of health care and the level of medical expenditures. It includes information on the demographic, social and economic characteristics of households and the status of medical use, such as chronic diseases, medicine, emergency, hospitalization, and primary services, and the status of private health insurance. The KHP collected data using face-to-face interviews and a self-entry method. Focusing exclusively on EMS satisfaction metrics, a total of 4,216 individuals were included in the study sample. The survey design was stratified cluster sampling framed by the national population and housing census conducted in 2005. The stratified cluster sampling method was implemented in 16 metropolitan cities (provinces) and towns (eup, myeon, dong) across the country as stratified variables. To obtain a representative estimate from the sample size, weights were applied to logistic regression analyses.

\section{Variable definitions}

Based on a literature review, the following variables were defined. The independent variables included the characteristics of the users and the characteristics of service processes. The variables related to the characteristics of service users included age, gender, education, marital status, residence, income, health status, number of ER visits, and whether the respondent is a patient or a proxy. The variables related to the characteristics of service processes included reasons for visiting the $\mathrm{ER}$, transportation to the ER, waiting time in the ER, and post-service measures. For the logistic regression analysis, the independent variables were re-coded for dichotomies. The first category for a variable was coded 1 and the reference category for it (after "vs.") was 0 . There were a few survey data issues, e.g., a few individuals did not provide their health status ( $\mathrm{n}=248$, or $5.9 \%$ of the sample) or post-service measures $(\mathrm{n}=71$, or $1.7 \%$ of the sample).

The dependent variable in this study is the satisfaction level of EMS for emergency medical users. Satisfaction with EMS was measured on a four-point-scale (very unsatisfactory, unsatisfactory, satisfied, and very satisfied) during the survey, and for this study the authors dichotomized dependent variable measures as "satisfied/very satisfied (1) or unsatisfactory/unsatisfactory" (0).

\section{Statistical analysis}

The data processing and analysis in this study was performed by SAS 9.4 software (SAS Institute Inc., 2020). Firstly, descriptive statistics such as mean, standard deviation (SD), percentages, and $\chi^{2}$ test were used to analyze the individual characteristics of the sample. Then, using logistic regression analysis, the factors in predicting EMS satisfaction were examined in more detail. Also, logistic regression analysis was used to control potential confounding variables. All tests were conducted at the $5 \%$ level of significance. The odds ratio (OR) was reported with a $95 \%$ confidence interval (CI).

\section{Results}

\section{Sample characteristics}

The general characteristics of the respondents are presented in Table 1. The average age of the respondents was $75.73( \pm 6.75)$ years old, with $89.04 \%$ of the respondents being female. $60.77 \%$ of the respondents were unmarried/divorced/separated/widowed. With regard to education, $23.46 \%$ of the respondents had no schooling, $47.06 \%$ primary schooling, $15.06 \%$ middle schooling, $11.03 \%$ high schooling, and $3.39 \%$ college schooling or higher. The average annual household income was $10.37( \pm 19.18)$ million won. More specifically, $44.92 \%$ of the respondents earned no family income, $37.86 \%$ earned 20 million won or less, and $17.22 \%$ earned 20 million won or more. $72.94 \%$ of the respondents resided in non-capital areas, while $27.06 \%$ resided in capital areas. In response to questions about self-perceived/ reported health, $52.12 \%$ of the respondents evaluated their health as poor or very poor, and $47.88 \%$ evaluated their health as fair, good, or very good. Those on their first visit to the emergency room was $74.31 \%$, $16.48 \%$ for the second and $9.21 \%$ for the third. $73.13 \%$ of those who responded were patients and the remaining $26.87 \%$ were proxies. For the reasons for visiting the emergency room, $24.31 \%$ of the respondents were because of accident or addiction and $75.69 \%$ were diseases. For the means of transportation used, $34.25 \%$ of the respondents used 119 or an ambulance, $47.06 \%$ a private car, $13.38 \%$ a taxi, and $5.31 \%$ walked. The average waiting time of the respondents was $1.03( \pm 0.17)$ minutes. Specifically, the waiting time of $59.04 \%$ of the respondents did not exceed 20 minutes while that of $40.56 \%$ of the respondents exceeded 20 minutes. $39.13 \%$ of the respondents were hospitalized after emergency services, $1.69 \%$ were transferred to other hospitals, and $59.18 \%$ returned home. 3,580 (84.91\%) out of 4,216 respondents said they were satisfied with EMS and 636 (15.09\%) said they were dissatisfied, indicating that they were generally satisfied.

\section{Difference in EMS satisfaction by independent variables}

Those who were most likely to have been satisfied with EMS were primarily those who were 75 and older, had primary schooling, rated their health as fair, good, or very good, had no income, lived in a noncapital area, made their first visit to the ER, said that the respondent was a patient, answered that the reason for visiting the ER was an accident or addiction, responded that the means of transportation used to go to the ER was a private car, said that the waiting time in the ER was less than 20 minutes, and returned home after receiving emergency services (Table 2).

In the initial stage of the analyses, variables such as age, education, income, residence, number of ER visits, health status, those who respond, reasons for visiting the ER, transportation to the ER, waiting 
Table 1. Characteristics of the sample $(\mathrm{N}=4,216)$

\begin{tabular}{|c|c|c|}
\hline Variables & $\mathbf{N}(\%)$ & Mean $( \pm$ SD $)$ \\
\hline Age group (years) & & $75.73( \pm 6.75)$ \\
\hline $65-74$ & $1,962(46.54)$ & \\
\hline $75+$ & $2,254(53.46)$ & \\
\hline \multicolumn{3}{|l|}{ Sex } \\
\hline Male & $462(10.86)$ & \\
\hline Female & $3,754(89.04)$ & \\
\hline \multicolumn{3}{|l|}{ Education } \\
\hline No schooling & $989(23.46)$ & \\
\hline Primary schooling & $1,984(47.06)$ & \\
\hline Middle schooling & $635(15.06)$ & \\
\hline High schooling & $465(11.03)$ & \\
\hline College schooling + & $143(3.39)$ & \\
\hline \multicolumn{3}{|l|}{ Marital status } \\
\hline Married & $1,654(39.23)$ & \\
\hline Others & $2,562(60.77)$ & \\
\hline \multicolumn{3}{|l|}{ Health status } \\
\hline Poor & $2,068(52.12)$ & \\
\hline Fair+ & $1,900(47.88)$ & \\
\hline \multicolumn{3}{|l|}{ Income (million won) } \\
\hline 0 & $1,894(44.92)$ & \\
\hline $1-20$ & $1,598(37.86)$ & $10.37( \pm 19.18)$ \\
\hline $20+$ & $726(17.22)$ & \\
\hline \multicolumn{3}{|l|}{ Residence } \\
\hline Capital area & $1,141(27.06)$ & \\
\hline Non-capital area & $3,075(72.94)$ & \\
\hline \multicolumn{3}{|l|}{ Visiting times } \\
\hline 1 & $3,133(74.31)$ & \\
\hline $2+$ & $695(16.48)$ & \\
\hline $3+$ & $388(9.21)$ & \\
\hline \multicolumn{3}{|l|}{ Those who respond } \\
\hline Patient & $3,083(73.13)$ & \\
\hline Proxies & $1,133(26.87)$ & \\
\hline \multicolumn{3}{|l|}{ Reasons for visiting ER } \\
\hline Accident/addiction & $1,025(24.31)$ & \\
\hline Disease & $3,191(75.69)$ & \\
\hline \multicolumn{3}{|l|}{ Transportation to ER } \\
\hline 119/ambulance & $1,444(34.25)$ & \\
\hline Private car & $1,984(47.06)$ & \\
\hline Taxi & $564(13.38)$ & \\
\hline Walking & $224(5.31)$ & \\
\hline \multicolumn{3}{|l|}{ Waiting time (minutes) } \\
\hline $0-20$ & $2,510(59.04)$ & \\
\hline $20+$ & $1,706(40.56)$ & $1.03( \pm 0.17)$ \\
\hline \multicolumn{3}{|l|}{ Post-service measures } \\
\hline Admitted & $1,622(39.13)$ & \\
\hline Transfer to other hospital & $70(1.69)$ & \\
\hline Returned home & $2,455(59.18)$ & \\
\hline \multicolumn{3}{|l|}{ EMS satisfaction status } \\
\hline Unsatisfied & $636(15.09)$ & \\
\hline Satisfied & $3,580(84.91)$ & \\
\hline
\end{tabular}

\#Korean monetary unit (\$US $1=$ KRW 1,230).

time in the ER, and post- service measures remained significant predictors of EMS satisfaction.

\section{Factors that affect satisfaction with EMS}

After controlling all the independent variables, variables that were statistically significant in the bivariate analysis were included in the logistic regression analysis to investigate variables that affect the satisfaction of EMS. The results are shown in Table 3. Age (OR, 0.817,
95\%CI:0.679-0.983, p=0.032), education (OR, 0.849, 095\%CI:0.773$0.933, \mathrm{p}<0.01$ ), number of ER visits (OR, 0.754,95\%CI:0.619$0.919, \mathrm{p}<0.01)$, whether the respondent is a patient or a proxy (OR, 0.629,95\%CI:0.516-0.768, $\mathrm{p}<0.01$ ), reasons for visiting ER (OR, $0.708,95 \%$ CI:0.565-0.888, $\mathrm{p}<0.01)$, waiting time in the ER (OR, 0.759, 95\%CI:0.613-0.939, $\mathrm{p}=0.011$, and post-services measures (OR, $0.862,95 \% \mathrm{CI}: 0.782-0.950, \mathrm{p}<0.01)$ were inversely associated with the satisfaction with EMS. Residence (OR, 1.325, 95\%CI:1.287-1.616, $\mathrm{p}<0.01)$ and health status (OR, 1.353,95\%CI:1.125-1.627, $\mathrm{p}<0.01)$ were significantly associated with EMS satisfaction.

Table 2. Percentage of those who satisfied emergency services by each variable $(\mathrm{N}=4,216)$

\begin{tabular}{|c|c|c|}
\hline \multirow{2}{*}{ Variables } & \multicolumn{2}{|c|}{ Emergency service satisfaction } \\
\hline & Percentage & $P$ \\
\hline Age group (years) & & $<0.05$ \\
\hline $65-74$ & 40.11 & \\
\hline $75+$ & 44.81 & \\
\hline Sex & & 0.06 \\
\hline Male & 8.99 & \\
\hline Female & 75.93 & \\
\hline Level of education & & $<0.01$ \\
\hline No schooling & 19.81 & \\
\hline Primary schooling & 39.8 & \\
\hline Middle schooling & 13 & \\
\hline High schooling & 9.06 & \\
\hline College schooling + & 3.25 & \\
\hline Marital status & & 0.09 \\
\hline Married & 51.11 & \\
\hline Others & 33.81 & \\
\hline Health status & & $<0.01$ \\
\hline Poor & 41.33 & \\
\hline Fair+ & 43.04 & \\
\hline Income (million won) & & $<0.01$ \\
\hline 0 & 37.76 & \\
\hline $1-20$ & 31.76 & \\
\hline $20+$ & 15.39 & \\
\hline Residence & & $<0.05$ \\
\hline Capital area & 22.41 & \\
\hline Non-capital area & 62.5 & \\
\hline Visiting times & & $<0.01$ \\
\hline 1 & 63.97 & \\
\hline $2+$ & 20.94 & \\
\hline Those who respond & & $<0.01$ \\
\hline Patient & 63.54 & \\
\hline Proxies & 21.37 & \\
\hline Reasons for visiting ER & & $<0.01$ \\
\hline Accident/addiction & 21.3 & \\
\hline Disease & 63.61 & \\
\hline Transportation to ER & & $<0.01$ \\
\hline 119/ambulance & 28.54 & \\
\hline Private car & 40.46 & \\
\hline Taxi & 11.05 & \\
\hline Walking & 4.86 & \\
\hline Waiting time (minutes) & & $<0.01$ \\
\hline$<10$ & 23.94 & \\
\hline Oct-20 & 25.83 & \\
\hline $20+$ & 35.15 & \\
\hline Post-service measures & & $<0.01$ \\
\hline Admitted & 32.57 & \\
\hline Transfer to other hospital & 0.53 & \\
\hline Returned home & 51.92 & \\
\hline
\end{tabular}

\#Korean monetary unit (\$US 1= KRW 1,230). 
Table 3. Multivariate logistic regression analysis of factors of EMS satisfaction for older Koreans, weighted $(\mathrm{N}=4,216)$

\begin{tabular}{|c|c|c|}
\hline \multirow{2}{*}{ Variables } & \multicolumn{2}{|c|}{ Emergency service satisfaction } \\
\hline & Percentage & $\boldsymbol{P}$ \\
\hline Age group (years) & & $<0.05$ \\
\hline $65-74$ & 40.11 & \\
\hline $75+$ & 44.81 & \\
\hline Sex & & 0.06 \\
\hline Male & 8.99 & \\
\hline Female & 75.93 & \\
\hline Level of education & & $<0.01$ \\
\hline No schooling & 19.81 & \\
\hline Primary schooling & 39.8 & \\
\hline Middle schooling & 13 & \\
\hline High schooling & 9.06 & \\
\hline College schooling + & 3.25 & \\
\hline Marital status & & 0.09 \\
\hline Married & 51.11 & \\
\hline Others & 33.81 & \\
\hline Health status & & $<0.01$ \\
\hline Poor & 41.33 & \\
\hline Fair+ & 43.04 & \\
\hline Income (million won) & & $<0.01$ \\
\hline 0 & 37.76 & \\
\hline $1-20$ & 31.76 & \\
\hline $20+$ & 15.39 & \\
\hline Residence & & $<0.05$ \\
\hline Capital area & 22.41 & \\
\hline Non-capital area & 62.5 & \\
\hline Visiting times & & $<0.01$ \\
\hline 1 & 63.97 & \\
\hline $2+$ & 20.94 & \\
\hline Those who respond & & $<0.01$ \\
\hline Patient & 63.54 & \\
\hline Proxies & 21.37 & \\
\hline Reasons for visiting ER & & $<0.01$ \\
\hline Accident/addiction & 21.3 & \\
\hline Disease & 63.61 & \\
\hline Transportation to ER & & $<0.01$ \\
\hline 119/ambulance & 28.54 & \\
\hline Private car & 40.46 & \\
\hline Taxi & 11.05 & \\
\hline Walking & 4.86 & \\
\hline Waiting time (minutes) & & $<0.01$ \\
\hline$<10$ & 23.94 & \\
\hline Oct-20 & 25.83 & \\
\hline $20+$ & 35.15 & \\
\hline Post-service measures & & $<0.01$ \\
\hline Admitted & 32.57 & \\
\hline Transfer to other hospital & 0.53 & \\
\hline Returned home & 51.92 & \\
\hline
\end{tabular}

Likelihood Ratio Test: $-2 \log \mathrm{L}=3,364.706, \mathrm{X} 2=108.146, p<0.0001$

ER: emergency room, OR: odds ratio, CI: confidence interval

*Results were adjusted for all other independent variables of Table 3.

\#Korean monetary unit (\$US $1=$ KRW 1,230).

Source: Korean Health Panel Survey (2016).

\section{Discussion}

Using the 2016 KHPS data, we documented the factors that affect the satisfaction level as well as differences in satisfaction with EMS. The results are similar to other studies [3,5]. In this study, the proportion of dissatisfaction with EMS was 15.09\%, which is higher than other studies. For example, according to a recent survey on medical service satisfaction, the proportion of dissatisfaction with EMS in large hospitals, which account for the majority of inpatients, was $13.0 \%$, and the degree of dissatisfaction with medical services in hospitals and clinics with most outpatients was $9.0 \%$ [15]. Therefore, it is necessary to improve EMS compared to hospitalization and outpatient services.

Differences in EMS satisfaction by general characteristics were not significant by gender, marital status and household income. This is the same result as other studies $[3,5]$. Other characteristic variables such as age, residence, health status, whether the respondent is a patient or a proxy, and number of ER visits had significant differences in EMS satisfaction. However, a study by Lee and others [9] showed that there is no difference in EMS satisfaction by age, sex, education, marital status, health status, whether the respondent is a patient or a proxy, and number of ER visits. Therefore, research on EMS satisfaction will continue to be needed depending on the general characteristics of the subjects.

Patients who visited the ER due to illness were found to be more satisfied with EMS than patients who visited the ER due to accident or addiction. This is the same result as research by Lee and others [9], and it was concluded that the patient who visited the hospital due to a longtime illness had higher stress than the patients who visited the hospital due to accident. On the other hand, studies by Lee and others [16] showed that patients who visited the ER due to accidents were more satisfied than those who visited the ER due to diseases. Most accidents are linked to urgent situations, and studies by Hangsagi and others [17] show that immediate and urgent patients are more satisfied than less urgent patients, and the results suggest that ER patient satisfaction is also related to the urgency of the situation [9].

In several studies related to the satisfaction level of EMS, the main unsatisfactory factors in ER use were transport delays and prolonged waiting. Delays in emergency patient transfer mean a delay in arrival at the ER and waiting for prolonged periods of time means waiting for treatment, or medical treatment after arrival in the ER. Studies in other countries show that patients' waiting time for treatment generally affects their satisfaction with EMS [18,19].

Although an investigation was not conducted in this study, institutional improvement measures are essential to solve the problem of transport delay in the emergency medical system. Meanwhile, some studies show that due to low medical links between emergency medical institutions, there is a delay in time to receive emergency treatment or a problem in which non-emergency patients are concentrated in ERs [20].

Patient satisfaction with EMS was higher when they returned home than when they were hospitalized or moved to another hospital. Several studies $[3,9,21]$ showed the same results. One study said that improvement of the symptoms of ER patients affects satisfaction with EMS [21]. The study said that patients' symptoms have improved when he or she returns home because he or she no longer needs treatment at the hospital. However, moving a patient to a higher hospital or another hospital can also be interpreted as requiring other high levels of treatment due to lack of improvement of symptoms or being moved to another hospital because they were not satisfied with the EMS provider [9]. Moving to other hospitals is caused by moving to specialized emergency medical institutions or having insufficient beds, or insufficient emergency medical personnel due to high severity after treatment and disease, which leads to complaints about EMS. For example, emergency surgery for patients with major arterial detachment is only possible in a small number of hospitals and there 
are many center-level hospitals where patients cannot be operated on in the case of special injuries such as finger amputation of severely traumatized patients, so the hospitals refuse to accept patients (e.g., absence of operating rooms, absence of intensive care rooms, etc.) due to hospital circumstances. In such cases, it is essential to move to another hospital, and misunderstandings and complaints arise in the process [3].

This study has some limitations. First, the data used in this study are panel survey data, but since only 2016 survey data were used for analysis, there are limitations in identifying the exact causal relationship between variables. Second, The Korea Health Panel Survey did not include information on the severity of patients related to EMS, so the study could not consider this as a variable. In addition, the limitation of the data in this study may lead to factors related to but not found in the satisfaction with EMS. These variables should be included in future EMS satisfaction studies. Third, among the respondents, there are more proxies than patients themselves, so the results of the study are limited to have representation that fully reflects the satisfaction with EMS for emergency patients. Finally, the accuracy of the responses may be reduced as a result of the survey based on the memory of the patient or proxy.

Despite these limitations, this research is significant in that it is a study of EMS satisfaction that has been carried out through representative national survey data. In the future, if KHPS data is continuously established and quality research using it is additionally conducted, it is expected to be used as government policy data to improve EMS.

In conclusion, $15.09 \%$ of older adults who are dissatisfied show the need to improve EMS. Characteristic variables such an age, residence, health status, whether the respondent is a patient or a proxy, and number of ER visits had significant differences in EMS satisfaction. Also, waiting time, reasons for visiting the emergency room, and postservice measures were factors that affected satisfaction that could be used as indicators of the quality of emergency medical services. For elderly Koreans, effective and rapid quality emergency medical services might be needed to avoid hospitalization or transfer to other hospitals and reduce waiting time in emergency rooms, especially for elderly patients who visited the emergency room because of an accident.

\section{Acknowledgements}

This work was supported by the Incheon National University Research Grant in 2019. A special word of thanks goes to the Korea Institute for Health and Social Affairs and the National Health Insurance Corporation, which provided the data from the 2016 Korea Health Panel Survey for this study.

\section{Conflict of interest}

No potential conflict of interest relevant to this article was reported.

\section{References}

1. National Emergency Medical Center. The annals of emergency medical statistics for 2014 [Internet]. Seoul: National Emergency Medical Center, 2015 [cited 2015 Aug 15] Available from: http://www.e-gen.or.kr/nemc/statistics_annual_report.do.

2. Je DW, Kim CH, Sung AJ, Seo JS, Ryoo HW, et al. (2007) Comparison and analysis of overall user satisfaction over 10 years in an emergency medical center. $J$ Korean Soc Emerg Med 18: 458-470.

3. Park JM, Lee TH, Lee SM, Lee JE (2019) Factors affecting the satisfaction of emergency medical services in capital and non-capital areas. J Korean Soc Emerg Med 30: $111-119$.

4. Cleary PD, McNeil BJ (1988) Patient satisfaction as an indicator of quality care Inquiry 25: 25-36.

5. Gil EH, Oh HY (2017) Factors influencing satisfaction with the emergency medical services between adults and the elderly Korean. J Adult Nurs 29: 12-21.

6. Taylor C, Benger JR (2004) Patient satisfaction in emergency medicine. Emerg Med J 21: 528-532

7. Messina G, Vencia F, Mecheroni S, Dionisi S, Baragatti L, et al. (2015) Factors affecting patient satisfaction with emergency department care: an Italian rural hospital. Glob J Health Sci 7: 30-39.

8. Lie Y, Jiang Y, Tang S, Qiu J, Zhong X, et al. (2015) Analysis of the equity of emergency medical services: a cross-sectional survey in Chongqing city. Int J Equity Health 14: 150.

9. Lee JC, Kim KH, Kim HN, Park YH (2011) Patient satisfaction with emergency medical services in Korea: what matters most? J Korean Soc Emerg Med 22: 299-308.

10. Park JO, Shin SD, Song KJ, Ahn KO, Hong KJ, et al. (2007) Factor for the dissatisfaction of patient for emergency department services. J Korean Soc Emerg Med 18: 97-106.

11. Kang KH (2013) Satisfaction gaps among physicians, nurses, and patient family in the emergency department. Health Policy Manag 23: 145-151.

12. Kim HJ, Yom YH (2011) The impact of patient satisfaction with nursing care services, switching costs and perceived risk on intention of reuse in the emergency medical center. J Korean Acad Nurs Adm 17: 432-442.

13. Khankeh HR, Khorasani-Zavareh D, Azizi-Naghdloo F, Hoseini MA, Rahgozar M (2013) Triage effect on wait time of receiving treatment services and patients satisfaction in the emergency department: example from Iran. Iran J Nurs Midwifery Res 18: 79-83.

14. Gerson LW, Rousseau EW, Hogan TM, Bernstein E, Kalbfleisch N (1995) Multicenter study of case finding in elderly emergency department patients. Acad Emerg Med 2: 729-734.

15. Korea statistical information service. Report on the social survey for 2014 [Internet] Daejeon: Statistics Korea, 2016 [cited 2016 Nov 23]. Available from: http://kosis.kr/ ups/ups_01List01.jsp?pubcode=KN.

16. Lee IJ, Choi KS (1997) A study on the regre of patients' satisfaction for medical service at emergency room. Nurs Sci Stud 1: 62-74.

17. Hangsagi H, Carlsson B, Brismar B (1992) The urgency of care need and patient satisfaction at a hospital emergency department. Health Care Manage Review 17: 7175 .

18. Seo KS, Kam S, Park JB, Lee JH, Kim JK, et al. (1998) Assessment of patients satisfaction and its related factors in the emergency department. J Korean Soc Emerg Med 9: 523-532.

19. Bursch B, Beezy J, Shaw R (1993) Emergency department satisfaction: What matters most? Ann Emerg Med 22: 586-591.

20. Moon SY, Kim SJ (2000) The degree of satisfaction with nursing care of pediatric patients visiting emergency center. J Korean Acad Child Health Nurs 6: 5-17.

21. Raper JL (1996) A cognitive approach to patient satisfaction with emergency department nursing care. J Nurse Care Qual 10: 48-58.

Copyright: (C2020 Park JM. This is an open-access article distributed under the terms of the Creative Commons Attribution License, which permits unrestricted use, distribution, and reproduction in any medium, provided the original author and source are credited. 